\title{
Pelvic tuberculosis: from millets to masses
}

\author{
Nitin H. Shah, Aditi V. Joshi*, Sunita Morya
}

Department of Obstetrics and Gynecology, Vardann Multispeciality Hospital, Kandivali, Mumbai, Maharashtra, India

Received: 13 May 2019

Revised: 30 May 2019

Accepted: 11 June 2019

\section{*Correspondence:}

Dr. Aditi V. Joshi,

E-mail: avj111@gmail.com

Copyright: (c) the author(s), publisher and licensee Medip Academy. This is an open-access article distributed under the terms of the Creative Commons Attribution Non-Commercial License, which permits unrestricted non-commercial use, distribution, and reproduction in any medium, provided the original work is properly cited.

\begin{abstract}
An adnexal mass is a common entity in the reproductive age group. Ovarian masses form a majority of this condition. Tuberculosis is a disease commonly encountered in the Tropics and is endemic to India. Abdominopelvic affliction of this disease is common in women especially in the reproductive age groups. It may present with variety of nonspecific clinical features and often poses an enormous diagnostic dilemma Author report one such case, presenting with a clinical impression of ovarian malignancy, however, was diagnosed to be a case of extensive pelvic tuberculosis on laparoscopy. Tissue biopsy was consistent with the finding of tuberculosis.
\end{abstract}

Keywords: Laparoscopy, Pelvic mass, Pelvic tuberculosis

\section{INTRODUCTION}

Abdominopelvic tuberculosis is a perplexing condition to diagnose. Incidence of pelvic tuberculosis in India varies between $3-16 \%$ and most patients are diagnosed during workup for infertility. ${ }^{1}$ Clinical presentation is often nonspecific and radiological manifestations may not be detected until late.

Patients may often have a vague clinical presentation, similar to those with an ovarian malignancy. Often CA125 may also be elevated in tuberculosis with peritoneal involvement. ${ }^{2,3}$ A judicious approach and establishment of a histopathological diagnosis is of prime importance to ensure a complete and effective treatment to the patient and avoid unnecessary radical procedures. ${ }^{4,5}$

\section{CASE REPORT}

A 39 year old, para 2 with two living issues, presented with symptoms of intermittent pain in abdomen, vague abdominal fullness and loss of appetite over the past few months. She did not have any significant past medical or surgical history. On examination her body mass index was $23.8 \mathrm{~kg} / \mathrm{m} 2$, pulse rate was $86 / \mathrm{min}$, blood pressure 140/80 mmHg, no evidence of pallor, icterus, cyanosis or lymphadenopathy. On cardiovascular and respiratory system examination no abnormality was detected. On abdominal examination, abdomen was soft but slightly distended, no organomegaly detected. However, ascites was felt on percussion. On per vaginal examination, uterus was retroverted with restricted mobility and fornical fullness was felt on both sides. On further investigations, CA 125 was elevated $(358 \mathrm{U} / \mathrm{ml})$, rest blood investigations were within normal limits. Ultrasound was suggestive of bilateral tubo-ovarian masses around $6 \mathrm{~cm}$ with presence of ascites. Unfortunately owing to the cost factor, an MRI could not be done for this patient.

A provisional diagnosis of ovarian malignancy was made. A decision for diagnostic laparoscopy was taken. 
Intraoperatively the entire peritoneal cavity was seen to be studded with small tubercles (Figures 1, 3, 4). Bilateral tubo-ovarian masses were noted with ascites and flimsy peritoneal adhesions (Figure 2).

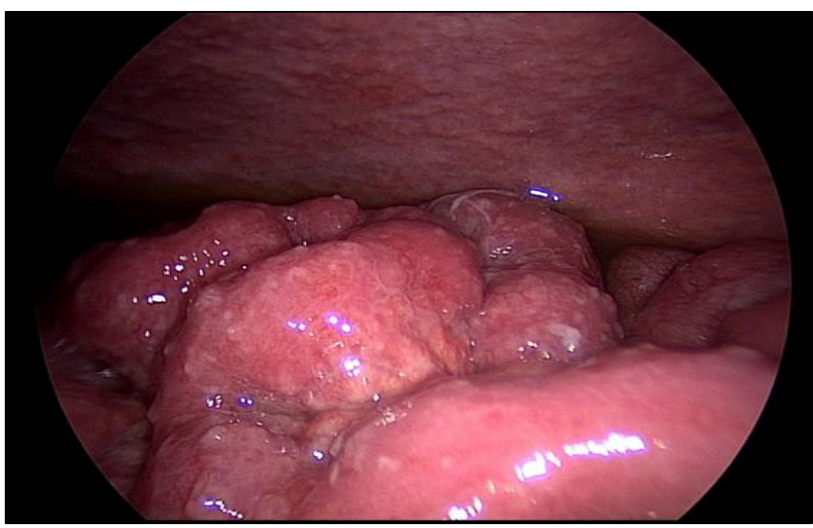

Figure 1: Illustrates the first view after entry into the abdomen via the primary port. There was presence of ascites with the pelvic cavity studded with small millet shaped nodules.

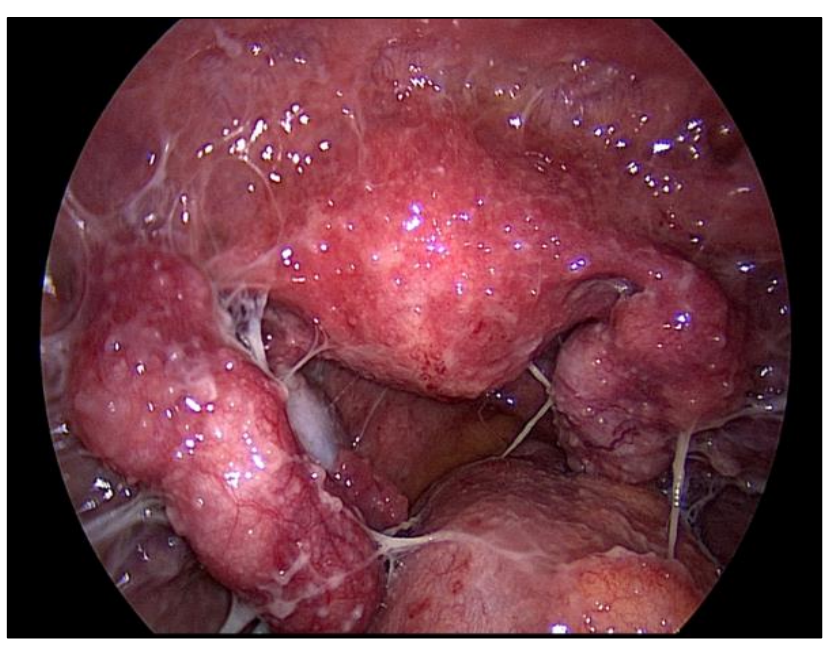

Figure 2: This figure depicts the uterus and adnexa studded with tubercles and presence of flimsy adhesions all over.

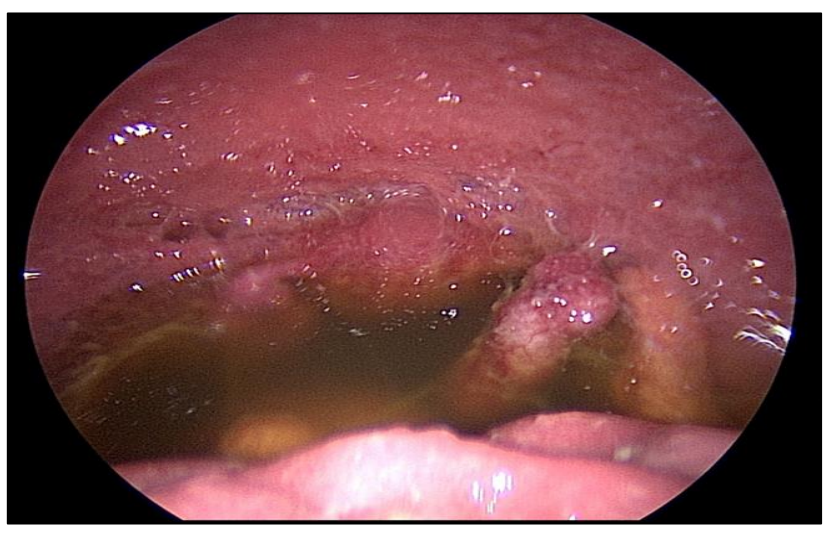

Figure 3: Frozen pelvis.

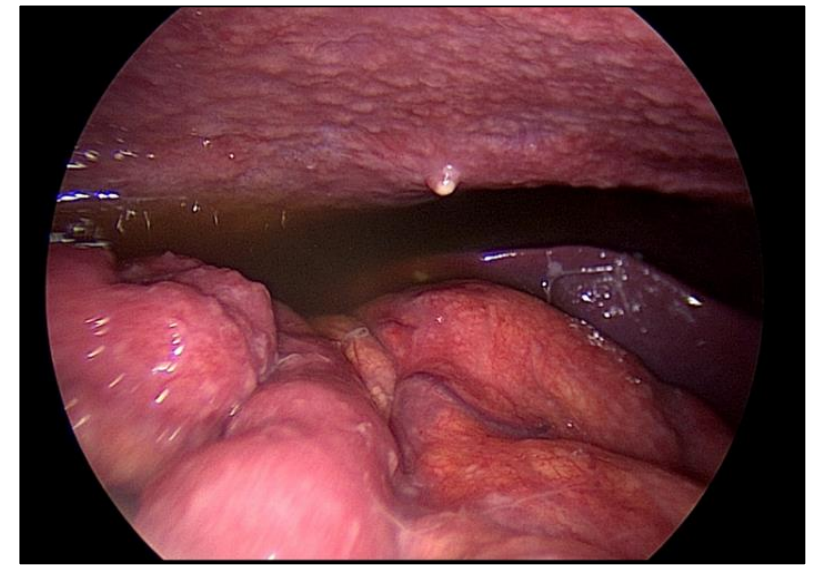

Figure 4: Tubercles on the under-surface of liver and anterior peritoneal surface with matted bowel loops.

A provisional diagnosis of military tuberculosis was made. The ascitic fluid was aspirated for ADA (adenosine deaminase) levels and cytology and an omental biopsy was taken.

ADA levels were $44 \mathrm{U} / \mathrm{ml}$. Cytology report showed absence of malignant cells and biopsy report showed necrotizing granulomatous inflammation, confirming the diagnosis of tuberculosis. GeneXpert revealed drug sensitive tuberculosis. She was then registered with the local DOTS (Directly Observed Treatment Short course) centre and put on Category 1 antitubercular drugs which comes under the national programme to curb tuberculosis.

\section{DISCUSSION}

Abdominopelvic tuberculosis is one of the commonest sites to be involved via extra-pulmonary spread. This accounts for $4 \%$ of extra pulmonary cases. ${ }^{6}$ It has a myriad presentation which includes non-specific symptoms like fatigue, low grade fever, abdominal fullness, abdominal pain, lower back pain, loss of appetite, weight loss etc which often mimic advanced ovarian malignancy. Abdominal tuberculosis can have a widespread involvement with miliary pattern of spread.

Most investigations are often inconclusive. Isolating mycobacterium tuberculosis from ascitic fluid is difficult and possible in merely $50 \%$ of the cases. Confirmation of mycobacterium tuberculosis via culture takes 6 weeks which delays treatment and can be detrimental in some cases that turn out to be a malignancy. Polymerase chain reaction (PCR) is an expensive investigation but can help in confirming the diagnosis. Serum adenosine deaminase (ADA) levels may form an effective screening tool due to its high sensitivity $(96 \%)$ and specificity $(98 \%){ }^{2}$

CA 125 is a non-specific tumor marker often elevated in a variety of conditions like endometriosis, PID, tuberculosis, ovarian malignancy etc. Hence it may not be ideal for diagnosis, however once treatment has been 
commenced following a conclusive diagnosis, it can have a prognostic value. ${ }^{7}$ Ultrasonography findings often mimic advanced ovarian malignancy with presence of bilateral pelvic masses having internal septations and indistinct margins with ascites. Other radiological investigations like computed tomography are often nonconclusive. However, a sensitivity of $91 \%$ and $67 \%$ for ovarian carcinoma and peritoneal tuberculosis respectively has been reported. ${ }^{8}$

Chest radiography maybe normal in almost $40 \%$ patients. ${ }^{9}$ While considering the treatment plan in such patients it is necessary to consider the age, ethnicity, CA 125 levels, ascitic fluid examination and a histopathological confirmation of the diagnosis. An establishment of the diagnosis pre-operatively is often difficult due to the non-specific nature of most investigations. Although ovarian malignancy has a greater prevalence than pelvic tuberculosis, it is necessary to establish a tissue diagnosis before commencement of treatment.

Tissue diagnosis primarily involves a peritoneal/ omental biopsy which can be accomplished either laparoscopically or via laparotomy. However, laparoscopy is the gold standard for diagnosis for peritoneal tuberculosis with a sensitivity of $93 \%$ and specificity $98 \%$ when combined with histological diagnosis. ${ }^{1}$ Studies have shown the importance of a tissue diagnosis which can prevent unnecessary surgery since medical therapy is the mainstay of treatment in tuberculosis. ${ }^{4,11}$

\section{CONCLUSION}

Laparoscopy has many advantages over a conventional laparotomy which includes shorter stay, less operative time and need for analgesia and faster recovery time. Hence, laparoscopic tissue biopsy should be considered a standard modality of approach in order to avoid extensive surgery to establish a diagnosis in difficult cases.

Funding: No funding sources Conflict of interest: None declared

Ethical approval: Not required

\section{REFERENCES}

1. Sharma JB. Current Diagnosis and Management of Female Genital Tuberculosis. J Obstet Gynaecol India . Springer. 2015;65(6):362-71.

2. Koc S, Beydilli G, Tulunay G, Ocalan R, Boran N, Ozgul N, et al. Peritoneal tuberculosis mimicking advanced ovarian cancer: A retrospective review of 22 cases. Gynecol Oncol. 2006;103(2):565-9.

3. Sevinc A, Adli M, Kalender ME, Camci C. Benign causes of increased serum CA-125 concentration. Lancet Oncol. 2007;8(12):1054-5.

4. Boss JD, Shah CT, Oluwole O, Sheagren JN. TB peritonitis mistaken for ovarian carcinomatosis based on an elevated CA-125. Case Report Med. 2012, 2012:215293.

5. Zaidi SN, Conner M: Disseminated peritoneal tuberculosis mimicking metastatic ovarian cancer. South Med J. 2001;94(12):1212-4.

6. Ozan H, Ozerkan K, Orhan A. Peritoneal tuberculosis mimicking peritoneal carcinomatosis. Eur J Gynaecol Oncol. 2009;30(4):426-30.

7. Thakur V, Mukherjee U, Kumar K. Elevated Serum Cancer Antigen 125 Levels in Advanced Abdominal Tuberculosis. Med Oncol. 2001;18(4):289-92.

8. Ha HK, Jung JI, Lee MS, Choi BG, Lee MG, Kim $\mathrm{YH}$ et al. CT differentiation of tuberculous peritonitis and peritoneal carcinomatosis. AJR Am J Roentgenol. 1996;167(3):743-8.

9. Bhattacharyya SK, Mandal A, Thakur SB, Mukherjee S, Saha SK, Ghoshal AG. Radiological evaluation of chest in abdominal tuberculosis. J Clin Diagn Res. 2011;5(5):926-8.

10. Tinelli A, Malvasi A, Vergara D, Martignago R, Nicolardi G, Tinelli R, et al. Abdominopelvic tuberculosis in gynaecology: Laparoscopical and new laboratory findings. Aust New Zeal J Obstet Gynaecol. 2008;48(1):90-5.

Cite this article as: Shah NH, Joshi A, Morya S.

Pelvic tuberculosis- from millets to masses. Int J Reprod Contracept Obstet Gynecol 2019;8:2943-5. 